\title{
Preparation and characterization of nano-structured tungsten carbide crystallites*
}

\author{
Hai-Ping $\mathrm{Xu}^{\dagger}$, Xiu-Juan Dai, Yue Zhai, Yan-Li Qin, \\ Cheng Xie and Wei Su \\ School of Environmental and Material Engineering, \\ Shanghai Polytechnic University, \\ Shanghai 201209, China \\ †E-mail:hpxu@sspu.edu.cn \\ www.sspu.edu.cn
}

\begin{abstract}
With $\mathrm{WCl}_{6}, \mathrm{C}_{2} \mathrm{H}_{2}$ and $\mathrm{H}_{2}$ reaction system and Ar work gas, WC nanocrystallites were prepared by plasma chemical vapor deposition(PCVD). The properties of $\mathrm{WCl}_{6}$ and $\mathrm{WC}$ particles including chemical composition, morphology, size and structure of crystal phase were characterized by Transmission Electron Microscopy (TEM) and X-ray Diffraction (XRD). Results show that the most particles of WC in the obtained nanocrystallites are spherical and the mean particle size is about $50 \mathrm{~nm}$.
\end{abstract}

Keywords: chemical vapor deposition; nano tungsten carbide; characterization.

\section{Introduction}

New materials have been playing one of the most vital roles in modern science and technology development. As the forerunner of new materials, nano technology has been developing since 1980s as the focus of the research worldwide[1], and there into hard alloy with nano structure has been concentrated in the research for powder metallurgy[2-4]. Reports indicated that if the size of tungsten carbide(WC) crystalline particle was under $1 \mu \mathrm{m}$, the hardness and tensile strength would increase synchronously, and the even remarkable increase of them could be observed for the nanostructured particle[5]. WC as a hard alloy with high hardness and tensity displays excellent performance in cutting processing, thus breaking the traditional conceptions that hardness increase brought up tensile strength decline. Preparing nanoscale WC particle by PCVD, only simple operations are needed to obtain samples of good

"This work was supported by Natural Science Foundation of Shanghai (No. 16ZR1412400), the Innovation Key Program of Shanghai Municipal Education Commission (No. 13ZZ140), Natural Science Foundation of Shanghai (No. 15ZR1417100), Key Discipline Construction of Shanghai Polytechnic University (Materials Science and Engineering, XXKZD1601). 
purity, thus creating an effective way to resolve the contradiction between hardness and tensile strength.

Solid phase reaction, liquid phase reaction and vapor phase reaction are the usual methods to prepare nano WC [6-9]. PCVD method is categorized as one way of the vapor phase reaction, which is characterized by high energy, fast reaction process, successive process and easy treatment with after-processing. Because reactants stay very short time in the plasma fire, they quickly cool down after leaving the fire, contributing to the small particle size, crystallization and sphere[10]. PCVD method is distinct for that it employs nonpolar discharge to prevent product from being polluted by melted or vaporized electrode at high temperatures. Also, it takes clean heat source and is easy to control. In this paper, nano WC microcrystal is prepared utilizing high frequency Ar as the heat source, $\mathrm{WCl}_{6}$ the tungsten source, $\mathrm{C}_{2} \mathrm{H}_{2}$ and $\mathrm{H}_{2}$ the reaction gas source, and Ar the burning and cooling gas, obtaining WC nanocrystallite of average diameter about 50nm.

\section{Experimental}

\subsection{Preparation of $\mathrm{WCl}_{6}$}

$\mathrm{WCl}_{6}$ as the raw and processed material is difficult to buy for its scarcity. In our experiments, $\mathrm{WCl}_{6}$ was obtained by the reaction of $\mathrm{Cl}_{2}$ and $\mathrm{W}$ powder at $600 \sim 800^{\circ} \mathrm{C}$ via the reaction formula

$$
\mathrm{W}+3 \mathrm{Cl}_{2}=\mathrm{WCl}_{6}(1)
$$

Put the quartz tube containing $\mathrm{W}$ powder into electric stove, whose temperature was controlled by temperature controlling device connected to thermocouples, provide $\mathrm{Cl}_{2}$ and keep it in reaction for 3-4 hours. Asbestos were put into the joint of quartz tube and electric stove in order to keep heat from dispersing.

\subsection{Preparation of $W C$}

WC was formed by vapor phase reactions in system $\mathrm{WCl}_{6}-\mathrm{C}_{2} \mathrm{H}_{2}-\mathrm{H}_{2}$, and the reaction was carried out in a high frequency plasma reactor using Ar as the fuel and cooling gas. Ar plasma of certain ionization constant was produced in the quartz tube thus creating high temperatures in the reactor of special structure. The mixed $\mathrm{WCl}_{6}, \mathrm{C}_{2} \mathrm{H}_{2}$ and $\mathrm{H}_{2}$ reactant gases which had been pre-heated were flowed through a vertical reactor and then reacted to form the product that condensed at a relative high deposition rate. The product was collected on filter paper at the reactor exit. The reaction formula is 


\subsection{Ample Characterization}

The morphology and aggregation situation and size of the microcrystal were observed by TEM (H-600-2, Tokyo, Japan), small amounts of particles were diluted in alcohol for 30 min's process of ultrasonic dispersing, and several drops of the sample were placed on $\mathrm{Cu}$ grids. The crystal phase was characterized by method of XRD (D/max-rB, Tokyo, Japan) using $\mathrm{CuK} \alpha$ radiation and HR-TEM (JEM-2010, Japan).

\section{Results and Discussion}

\section{1. $X R D$ spectrogram of $\mathrm{WCl}_{6}$}

Prepared $\mathrm{WCl}_{6}$ powders are generally crystals with brown color and with stable properties. Also, it contains a little bit of mauve powders, which changes light yellow for a period of time. Fig.1 shows the XRD spectrograms of the obtained powders. By studying the XRD patterns of the brown part (see Fig.1a), it is confirmed from comparison the interplanar spacing, $d$, of corresponding peaks with that of JCPDS standard card that this part of product is exactly $\mathrm{WCl}_{6}$ crystal, no impurities existed. It is known that reaction $\mathrm{W}+3 \mathrm{Cl}_{2} \rightarrow \mathrm{WCl}_{6}$ takes place at above $600^{\circ} \mathrm{C}$. If the $\mathrm{Cl}_{2}$ and $\mathrm{W}$ powder couldbe provided as hardly contained any impurities, the brown $\mathrm{WCl}_{6}$ crystal with high purity could be obtained at $600 \sim 800^{\circ} \mathrm{C}[11]$.

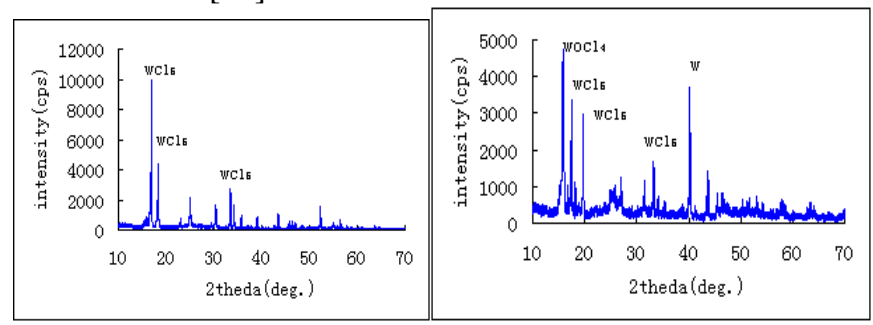

(a)(b)

Fig. 1. XRD patterns of the $\mathrm{WCl}_{6}$ product (a)the brown part and (b) the mixed product

Fig. $1 \mathrm{~b}$ is the XRD spectra of the very little amount of mauve powders. It can be seen from the spectra that $\mathrm{WCl}_{6}, \mathrm{WOCl}_{4}$ and little $\mathrm{W}$ powders are contained in this part. Analysis indicates that $\mathrm{WOCl}_{4}$ is resulted from the impurity of $\mathrm{Cl}_{2}$ or $\mathrm{W}$ powder. If $\mathrm{Cl}_{2}$ used in experiment contained any water vapor or air, it would bring the reaction

$$
\begin{array}{r}
\mathrm{W}+\mathrm{H}_{2} \mathrm{O}+3 \mathrm{Cl}_{2} \rightarrow \mathrm{WOCl}_{4}+2 \mathrm{HCl}(3) \\
2 \mathrm{~W}+\mathrm{O}_{2}+4 \mathrm{Cl}_{2} \rightarrow 2 \mathrm{WOCl}_{4}(4)
\end{array}
$$


Even slight amount of impurity WO in W powder, it also would result in $\mathrm{WOCl}_{4}$

$$
\mathrm{WO}+2 \mathrm{Cl}_{2} \rightarrow \mathrm{WOCl}_{4}(5)
$$

$\mathrm{WOCl}_{4}$ powders change its color from the initial mauve to light yellow over a period of time. And because of the low boiling point of $\mathrm{WOCl}_{4}$, it easily decomposes into $\mathrm{WO}_{3}$, which is light yellow, and WO containing slight amount of chlorine.

W powders in the sample come from W that didn't work together in the previous reaction, yet it wouldn't affect the quality of WC. XRD results show that the prepared material is $\mathrm{WCl}_{6}$ powders containing slight amount of impurity of $\mathrm{WOCl}_{4}$.

\section{2. $X R D$ spectrogramof $W C$}

Fig.2 shows the XRD spectrograms for powders prepared by plasma CVD. Analysis reveals that there are $\mathrm{WC}, \mathrm{W}_{2} \mathrm{C}$ and $\mathrm{WC}_{1-\mathrm{x}}$ containing in the product.

Generally, it is thought that WC preparation experienced two steps: the first deoxidize and then carbonize. Detailed dioxide process is illuminated as following

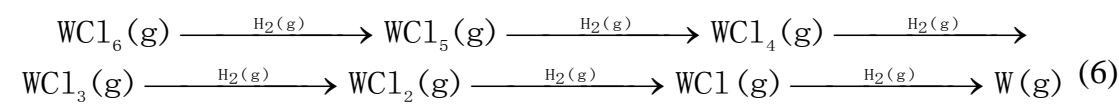

Because of the high temperature of plasma, hydrogen atom derived from $\mathrm{H}_{2}$ decomposition and further ionization to form $\mathrm{H}^{+}$. $\mathrm{H}$ and $\mathrm{H}+$ greatly enhance the deoxidizing ability of $\mathrm{H}_{2}$, as well as increase the chemical activity of hydrogen. $\mathrm{WCl}_{6}$ is vaporized and then is heated by the high temperature of plasma in the reactor, existing as the form of gas molecule instead of solid particles. Gas-gas reduction reaction between highly activated $\mathrm{H}_{2}$ and gaseous $\mathrm{WCl}_{6}$ produces highly active $\mathrm{W}$ atom. At the high temperature of plasma, $\mathrm{W}$ atoms and active carbon atoms from $\mathrm{C}_{2} \mathrm{H}_{2}$ collide against each other and combined in reaction. In the process, simple hexagonal WC crystal is formed through optimal grouping of W-C lattice movement, and further WC vapor comes into formation. Saturated WC vapor begins to condense and nucleate through homogenous nucleation when experiencing fast cooling, forming many minute groups, which would grow bigger and bigger if further cooled, finally forming WC nanocrystallites. 


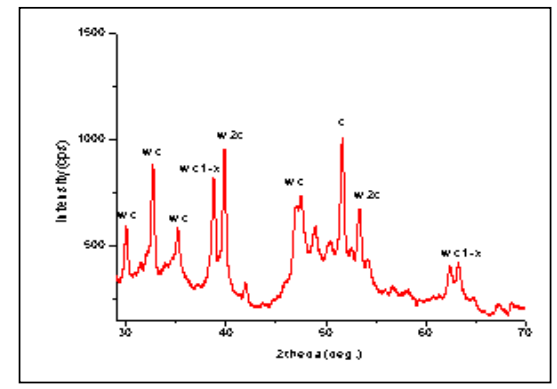

Fig. 2. XRD patterns of the WC product

At temperature as high as $2000 \mathrm{~K}$ or even higher, different product phases region, such as $\mathrm{W}_{2} \mathrm{C}, \mathrm{WC}_{1-\mathrm{x}}, \mathrm{WC}$, etc, would be distinct by different carbon concentration and reaction temperature. Because carbon concentration and temperature distribution in the reactor are not perfectly even, and synchronously with different reaction time, so different products are obtained under plasma condition. It is hard to prepare WC with high purity, usually, Tungsten carbide of other valence co-existed for the homogeneous phase of WC is really narrow, the influencing factor for WC formation is complicated and the particularly strict requirements for carbon concentration and temperature are needed.

\subsection{TEM and HR-TEM Analysis of WC}

Fig.3showsthe TEM and HR-TEM photographs for WC sample, respectively. It is observed from TEM shown in Fig.3a that most WC particles are ball-shaped and a few of them are stick-shaped or pack-shaped. They appear as aggregated groups with the average diameters of about $50 \mathrm{~nm}$. The corresponding HR-TEM photograph in Fig.3b shows that the particles with the form of aggregated groups are composed of many aggregated nanocrystallites with single, dense structure and $5-15 \mathrm{~nm}$ in diameter. The reason for aggregation resulted in small particle size with high surface activity, which could aggregate to reduce energy and keep stable states. Fig.3balso indicates that lattice constant, a, of the microcrystal is about $0.3 \mathrm{~nm}$, which coincides with that of WC lattice constant. All these led the conclusion that the obtained particles are WC nanocrystallites, and the product is the aggregations of WC nanocrystallites. Because the diameter of reactant entrance is smaller than the reactant entry pipe, reactant gases get into the reaction region by eject, getting well mixed. Product gas stream cool down to form particles by water. On the other hand, because the diameter of reaction region is much smaller than that of the cooling region, a sudden broadening exists at the joining point, this resulted the expansion and quencher for the product gas stream, thus preventing WC particles from growing bigger. From the TEM photograph of the few existing stick shape substances as 
shown in Fig.3c,it can be seen that they are composed of dense layers, hinting that they are single crystal.
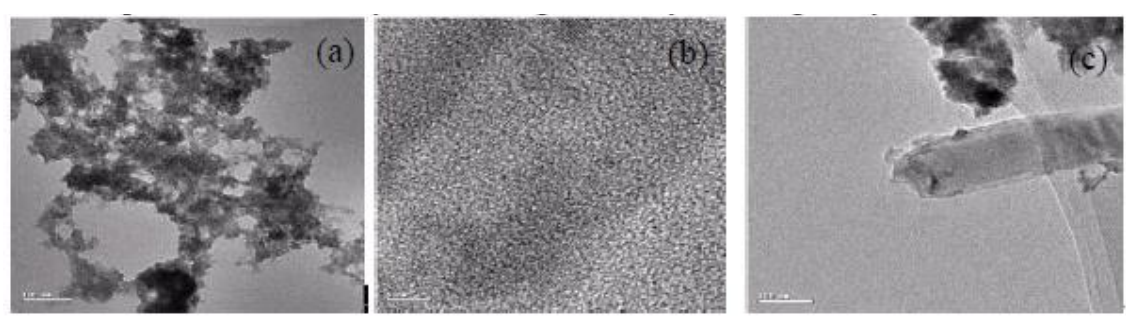

Fig. 3. Particle shape and size distribution of WC nanocrystallites (a) TEM photograph of WC, (b) HR-TEM photograph of WC, (c) TEM photograph for the stick-shaped WCproduct.

\section{Conclusion}

By providing $\mathrm{Cl}_{2}$ to tungsten powder in silica tube in electric stove at $600 \sim 800^{\circ} \mathrm{C}$, purple black and metal-shine $\mathrm{WCl}_{6}$ is obtained. Gray black hard WC nanocrystallitesare produced with $\mathrm{WCl}_{6}$ vapor, $\mathrm{C}_{2} \mathrm{H}_{2}$ and $\mathrm{H}_{2}$ as raw materials through RF-PCVD method.

XRD results indicate that the prepared $\mathrm{WCl}_{6}$ is of high purity, containing slight amount of mauve impurity $\mathrm{WOCl}_{4}$, which changes into light yellow $\mathrm{WO}_{3}$ and WO containing minor chloride. It is really difficult to obtain single product because WC powder prepared through PCVD displays a narrow homogeneous phase, and the requirements for temperature and carbon concentration are really rigor. TEM results show that most of WC particles are globular with average diameter about $50 \mathrm{~nm}$ and a few are stick shape or package shape. HR-TEM results show the lattice constant $\mathrm{a}=0.3 \mathrm{~nm}$, which coincides with that of WC crystal, indicating that the particles were all WC nanocrystallites.

\section{References}

1. C. Suryanarayana and C. C. Koch, Nanocrystalline Materials-current Research and Duture Directions. Hyperfine Interactions, 130, 3(2000).

2. K. Jiwoong,S. Y. Jae and K. Ilmo, First-principles calculations of the phase stability and the elastic and mechanical properties of eta-phases in the WCCo system. Journal of Alloys and Compounds, 656, 213(2016).

3. N. Nayebpashaee, M. Soltanieh and S. Kheirandish, A Study on Formation and Growth Mechanism of Nitride Layers During Plasma Nitriding Process of Plastic Injection Mold Steel. Materials and Manufacturing Processes, 31, 1192(2016).

4. Y. M. Sun, S. Y. Lee and A. M. Lemonds, Low temperature chemical vapor deposition of tungsten carbide for copper diffusion barriers. Thin Solid 
Films, 39,109(2001).

5. C. A.Ma, W. Wang and H. J. Zheng. PECVD nanostructure tungsten carbide thin films at low temperature. Heat Treatment of Metals,31, 20(2006).

6. F. Abdolali, M. Norhamidi, S. A. Bakar, Y. H. Shye, A. S.Y. M and R. Javad, Micro-Powder Injection Molding of Cemented Tungsten Carbide: Feedstock Preparation and Properties.Ceramics International,41, 3605(2015).

7. J. Sun, B. L. Liang, Y. Q. Huang and X. D. Wang, Synthesis of Nanostructured Tungsten Carbonitride (Wnxcy) By Carbothermal Ammonia Reduction on Activated Carbon and its Application In Hydrazine Decomposition. Catalysis Today, 274,123(2016).

8. L. S. Zhong, X. Zhang, S. L. Chen, Y. H. Xu, H. Wu and J. Wang, Fe-W-C Thermodynamics and in Situ Preparation of Tungsten Carbide-Reinforced Iron-Based Surface Composites by Solid-Phase Diffusion. International Journal of Refractory Metals and Hard Materials,57, 42(2016).

9. T. Dash and B. B.Nayak, Preparation of Multi-Phase Composite of Tungsten Carbide, Tungsten Boride and Carbon By Arc Plasma Melting: Characterization of Melt-Cast Product. Ceramics International,42,445(2016).

10. T. Kameyama, T. Tsunoda and A. Motoe, Preparation of ultrafine $\mathrm{WC}_{1-\mathrm{x}}$ powder in a R.F.thermal plasma and its properties. Journal of the Japan Society of Powder and Powder Metallurgy, 38,109(1991).

11. M. I. Boulos, X. L. Jiang, Effect of process parameters on induction plasma reactive deposition of tungsten carbide from tungsten metal powder. Trans Nonferrous Met Soc China, 11, 639(2001). 